\title{
The Positivity Effect on the Intensity of Experienced Emotion and Memory Performance in Mild Cognitive Impairment and Dementia
}

\author{
Lina Gorenc-Mahmutaj $^{a} \quad$ Christina Degen ${ }^{a} \quad$ Petra Wetzel ${ }^{a}$ \\ Nadja Urbanowitsch ${ }^{a}$ Joachim Funke ${ }^{b}$ Johannes Schröder ${ }^{a, c}$

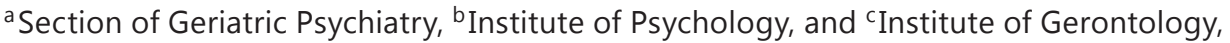 \\ University of Heidelberg, Heidelberg, Germany
}

Key Words

Pictures · Free recall $\cdot$ Recognition · Valence $\cdot$ Arousal

\begin{abstract}
Aims: We examined the 'positivity effect' on memory performance in mild cognitive impairment (MCI) and dementia patients. Methods: In 109 subjects ( 28 controls, 32 with MCI, 27 with mild and 32 with moderate dementia), we investigated free recalls (immediate and delayed) and recognition of 12 pictures. Moreover, the emotional valence of the pictures perceived and the emotions evoked in the subjects were evaluated. Results: Patients with mild and moderate dementia recalled fewer pictures than those with $\mathrm{MCI}$ or the healthy controls. Across the groups, the positive pictures were better memorized and induced a higher arousal than the negative or neutral ones. Conclusions: Our findings indicate a positivity effect on memory performance and intensity of experience not only in healthy elderly patients but also in those with $\mathrm{MCI}$ or mild and moderate dementia. This effect does not refer to the compliance of the patients investigated since they perceived and experienced the pictures in the expected way.
\end{abstract}

(c) 2015 S. Karger AG, Basel

\section{Introduction}

Experience and perception of emotions are essential; however, in the course of our life, they change. Thus, older adults show a preference for positive compared with negative stimuli in attention and memory [1,2]. Therefore, in memory tasks, older adults recalled more positive than negative or neutral words [1]. This preference for positive stimuli is called positivity effect. In what follows, several reasons are given for this effect. 
Carstensen [3] explained the effect with the socioemotional selectivity theory. She postulated that the relative importance of goals changes as a function of future time horizons. Young people have rather future-oriented goals related to gathering information and expanding horizons, which are prioritized over emotional gratification. The lifetime of older adults is limited, and so the primary goal is to obtain emotional satisfaction. Consistent with the theory, older age is associated with improved regulation of emotion, which involves the maintenance of positive affect and the decrease in negative affect $[4,5]$. This could be one reason for the finding that older adults experienced negative emotions less frequently $[4,5]$ and positive emotions as often as [4] if not more frequently [6] in daily life compared with young adults. In addition, we know that increased arousal while learning improves the declarative memory performance [7]. A particular example is the vivid memory of emotionally arousing events, such as receiving the news of the death of a relative. This is called 'flashbulb memory' phenomenon [8].

The improvement of explicit memory through emotional arousal is mediated by the amygdala [9]. An enhanced activation of this region was especially shown in young adults, particularly with negative emotions [10]. In contrast, Mather et al. [11] were able to show differences in the activation of the amygdala while experiencing positive and negative emotions among healthy older adults; i.e., the activity of the amygdala was decreased when experiencing negative emotions in comparison to younger adults, while it did not change when experiencing positive emotions. This reduced activity is simultaneously associated with subjectively less experienced arousal in negative emotions as well as a worse memory of these stimuli $[10,11]$. Also, in patients with Alzheimer's disease (AD), the amygdala appears to be partially functional. In a study by Mori et al. [12], a correlation between the volume of the amygdala and the emotional memory in AD was observed.

The main symptom in $\mathrm{AD}$ is the impairment of explicit memory. A potentially preliminary stage of AD, i.e. mild cognitive impairment (MCI), already manifests deficits in this area. Recall and recognition are affected. However, several studies showed a better memory performance if emotional stimuli are involved. For example, Ikeda et al. [13] found that patients with AD had a better memory performance for an earthquake than for an fMRI examination. Other authors detected a positivity effect for pictures and words $[14,15]$. In contrast, AbrisquetaGomez et al. [16] did not find an emotional effect for AD. As the results show, the influence of emotions on the memory performance is not yet clear. One reason could be the different stimulus materials that were used in the studies. For example, studies with illustrated stories [17-19], which are associated with more arousal than plain texts, continuously revealed an effect of emotion on memory in patients with AD. It is, therefore, plausible that dementia patients need a higher degree of arousal to improve their memory performance than healthy controls. This suggests that in an emotional memory task, the experienced arousal in AD patients should be investigated. Another reason for inconsistent results may lie in the sample size, and as a consequence thereof they lack statistical power. In part, the sample size was too small to detect any memory effect [14, 20,21].

Studies which investigated biological correlates show a compensatory role of emotionrelated networks. Grady et al. [22] reported that in AD patients only better memory performance correlated with an increased activation of the left amygdala, which in turn is associated with an increased activation of regions involved in emotional processing [cingulate, thalamus, insula, left prefrontal cortex (PFC)]. The left PFC is associated with positive emotions, a better working with negative emotions and their suppression, while the right PFC is activated in negative emotions [23]. Accordingly, in an fMRI study by Grimm et al. [24], hypoactivity of the left PFC and hyperactivity of the right PFC in individuals with major depression were found. Thus, there are both biological reasons as well as various emotion regulations which redound to the benefit of experience and memory performance of positive emotions in healthy controls and persons with different cognitive decline. 
Table 1. Clinical characteristics, MMSE and GDS scores across diagnostic groups (total: $n=109$ )

\begin{tabular}{lllll}
\hline Characteristic & $\begin{array}{l}\text { Healthy controls } \\
(\mathrm{n}=28)\end{array}$ & $\begin{array}{l}\text { MCI } \\
(\mathrm{n}=32)\end{array}$ & $\begin{array}{l}\text { Mild dementia } \\
(\mathrm{n}=27)\end{array}$ & $\begin{array}{l}\text { Moderate dementia } \\
(\mathrm{n}=22)\end{array}$ \\
\hline Age, years & $72.6 \pm 10.4$ & $78.4 \pm 17.1$ & $75.6 \pm 11.1$ & $81.7 \pm 8.8$ \\
Sex, $\mathrm{n}$ & 16 & 24 & 15 & 16 \\
$\quad$ Female & 12 & 8 & 12 & 6 \\
$\quad$ Male & $12.9 \pm 3.4$ & $12.5 \pm 3.4$ & $12.9 \pm 3.5$ & $11.4 \pm 3.4$ \\
Education, years & $28.2 \pm 0.9(27-30)$ & $24.9 \pm 0.9(24-26)$ & $21.7 \pm 1.3(19-23)$ & $14.8 \pm 2.7(7-18)$ \\
MMSE (range) & $2.9 \pm 2.9(0-14)$ & $3.3 \pm 2.8(0-11)$ & $3.6 \pm 2.9(0-10)$ & $3.8 \pm 3.5(0-11)$ \\
GDS (range) & & & &
\end{tabular}

GDS = Geriatric Depression Scale.

In the present study, we investigated the influence of emotional valence on the intensity of the experience and memory performance in $\mathrm{MCI}$ and dementia patients and the relationship between intensity and memory performance. We used a recall and recognition test that included emotional (positive and negative) and neutral pictures and a rating for the experience aroused by the pictures. Based on the presented literature, our hypotheses were as follows: we assumed that in all groups memory performance was better for positive stimuli than for negative and neutral stimuli for both immediate and delayed recall and for recognition. Furthermore, we expected that all groups experienced the positive images as the most intensive.

\section{Materials and Methods}

\section{Subjects}

A total of 165 subjects participated in the study; 56 subjects were excluded due to strong impairment of vision, hearing or speech skills. Accordingly, 109 subjects - 84 residents of nursing homes in different parts of Baden-Württemberg and 25 patients of the Memory Clinic of the University Clinic of Heidelberg - were included in our calculations. Clinical diagnosis was established by an experienced geriatric psychiatrist according to the criteria of age-associated cognitive decline (MCI) [25, 26] or ICD-10 criteria [27], respectively. On the basis of the nursing home records, 6 patients had AD and 1 patient had vascular dementia. The severity of the cognitive deficits was assessed using the Mini-Mental State Examination (MMSE) [28].

The clinical characteristics of the patients and controls are summarized in table 1 . As expected, the scores on the MMSE differed significantly between the four groups $\left(\mathrm{F}_{3}=361.252\right.$, $\mathrm{p}<0.001$ ). In contrast, age, gender, education and scores on the Geriatric Depression Scale [29] showed only minor, nonsignificant differences between the groups.

The study was approved by the Ethics Committee of the Medical Faculty of Heidelberg, and informed consent was obtained from all participants or their legal caregivers.

\section{Stimuli}

In this study, 24 pictures of the International Affective Picture System (IAPS) [30], a standardized set of affective stimuli, were presented on cards. Eight of these pictures were chosen to induce positive emotions and 8 to induce negative emotions, while 8 images conferred neutral emotions. The positive and negative pictures were equally composed of similar fields (e.g., animals, people, and objects). However, the neutral pictures consisted of objects only. For each picture, a presentation period of about $5 \mathrm{~s}$ was given. 


\section{Procedure: Emotion Memory Task}

\section{Presentation}

The participants were instructed to briefly describe each picture and to memorize it. The pictures were presented in two different sequences (positive-neutral-negative vs. negativeneutral-positive) to address possible position effects. The investigators scored whether or not a participant had correctly identified a picture.

\section{Memory Performance}

Free Recall. Immediately after the presentation phase, each participant was asked to recall all pictures. This procedure was repeated after $30 \mathrm{~min}$ to examine delayed recall. For the immediate and delayed recall, the participants were allowed $90 \mathrm{~s}$ at the most. The investigators recorded all pictures that were correctly remembered both during the immediate as well as the delayed recall.

Recognition. All participants were asked to identify the originally presented 12 pictures out of a sequence of 24 pictures ( 12 targets and 12 distractors matched to the targets regarding normative affective valence, normative arousal, and semantic characteristics). All pictures were presented in a random order. For each photograph, participants were instructed to respond 'yes' if they remembered the photograph from the earlier study phase and 'no' if they did not remember the photograph.

\section{Experience of the Picture}

Following the recognition test, subjects were asked to indicate their experience, both emotional valence (which emotions were experienced) and arousal (how intensive was the emotion they experienced), with each of the 12 pictures. The emotional valence and arousal rating by the subjects was performed using a visual analogue scale (very positive - positive - neutral - negative - very negative).

For statistical analyses, the rating scale was recoded as follows: for emotional valence, 'very positive, positive' $=1$, 'negative, very negative' $=2$, and 'neutral' $=0$, and for arousal, 'very positive, very negative' $=$ very intensive $=2$, 'positive, negative' $=$ intensive $=1$, and 'neutral' $=$ not intensive $=0$.

\section{Statistical Evaluation}

In a first step, all clinical variables were compared between the diagnostic groups; this was done by using either analysis of variance (ANOVA) or the $\chi^{2}$ test where appropriate. In a second step, the performance on the emotional memory task was compared between the groups by calculating a $3 \times 4$ ANOVA with repeated measures (the between-subject factor was 'diagnosis', the within-subject factor was 'emotional valence'). For significant results, pairwise comparison by the Bonferroni or the $t$ test with Bonferroni-Holm correction was performed. All computations were calculated using IBM SPSS Statistics 22 (German version). The significance level was set to $\alpha=5 \%$.

\section{Results}

\section{Presentation}

The accuracy of the picture description across all groups was high (positive pictures: 3.7 \pm 0.6 ; negative pictures: $3.7 \pm 0.5$; neutral pictures: $3.8 \pm 0.5$ ) and did not differ significantly between picture categories (diagnosis: $F_{3,105}=2.318$, n.s.; emotional valence: $F_{2,210}=2.742$, n.s.; diagnosis $\times$ emotional valence: $F_{6,210}=0.694$, n.s.). 


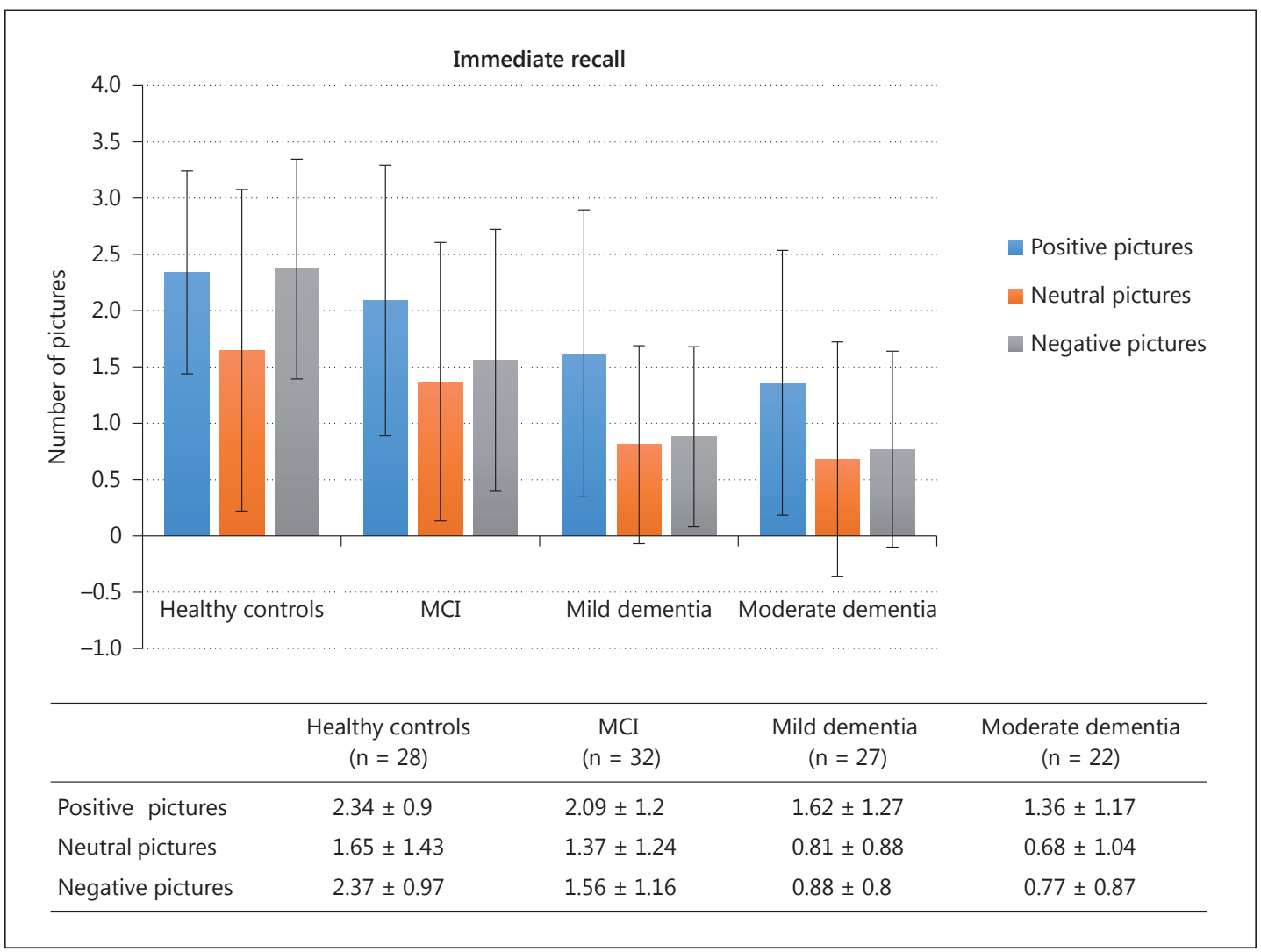

Fig. 1. Mean and standard deviation for the number of recalled positive, negative, and neutral pictures (immediate recall) considering healthy controls, patients with MCI and both dementia groups.

\section{Memory Performance}

Free Recall

Immediate Recall. The results of the immediate recall for all groups are presented in figure 1. The healthy controls and MCI patients recalled an equal amount of pictures (n.s.), and more pictures than patients with mild dementia (healthy: $p<0.001 / \mathrm{MCI}: \mathrm{p}=0.042$ ) and moderate dementia (healthy: $\mathrm{p}<0.001 / \mathrm{MCI}$ : $\mathrm{p}=0.006$; diagnosis: $\mathrm{F}_{3,105}=12.529, \mathrm{p}<0.001$ ). As predicted, positive pictures were recalled in greater numbers than negative pictures $(\mathrm{p}<$ $0.001)$, and negative pictures were recalled in greater numbers than neutral pictures $(\mathrm{p}=$ 0.029 ; emotional valence: $F_{2,210}=18.216, p<0.001$ ). These effects applied to all diagnostic groups (diagnosis $\times$ emotional valence: $\mathrm{F}_{6,210}=1.078$, n.s.).

Delayed Recall. The results of the delayed recall for all groups are presented in figure 2. The healthy controls recalled most pictures (MCI: $p=0.002 /$ mild dementia: $p<0.001 /$ moderate dementia: $\mathrm{p}<0.001$ ). The MCI patients and those with mild dementia recalled an equal amount of pictures (n.s.), and more pictures than patients with moderate dementia $(\mathrm{p}=0.005)$. No differences (n.s.) between patients with mild and those with moderate dementia was found (diagnosis: $F_{3,102}=14.789, p<0.001$ ). As predicted, positive pictures were recalled in greater numbers than negative $(\mathrm{p}<0.001)$ and neutral pictures $(\mathrm{p}=0.001)$. No differences emerged between negative and neutral pictures (n.s.; emotional valence: $F_{2,204}=9.297, p<0.001$ ). These effects applied to all diagnostic groups (diagnosis $\times$ emotional valence: $\mathrm{F}_{6,204}=0.550$, n.s.). 


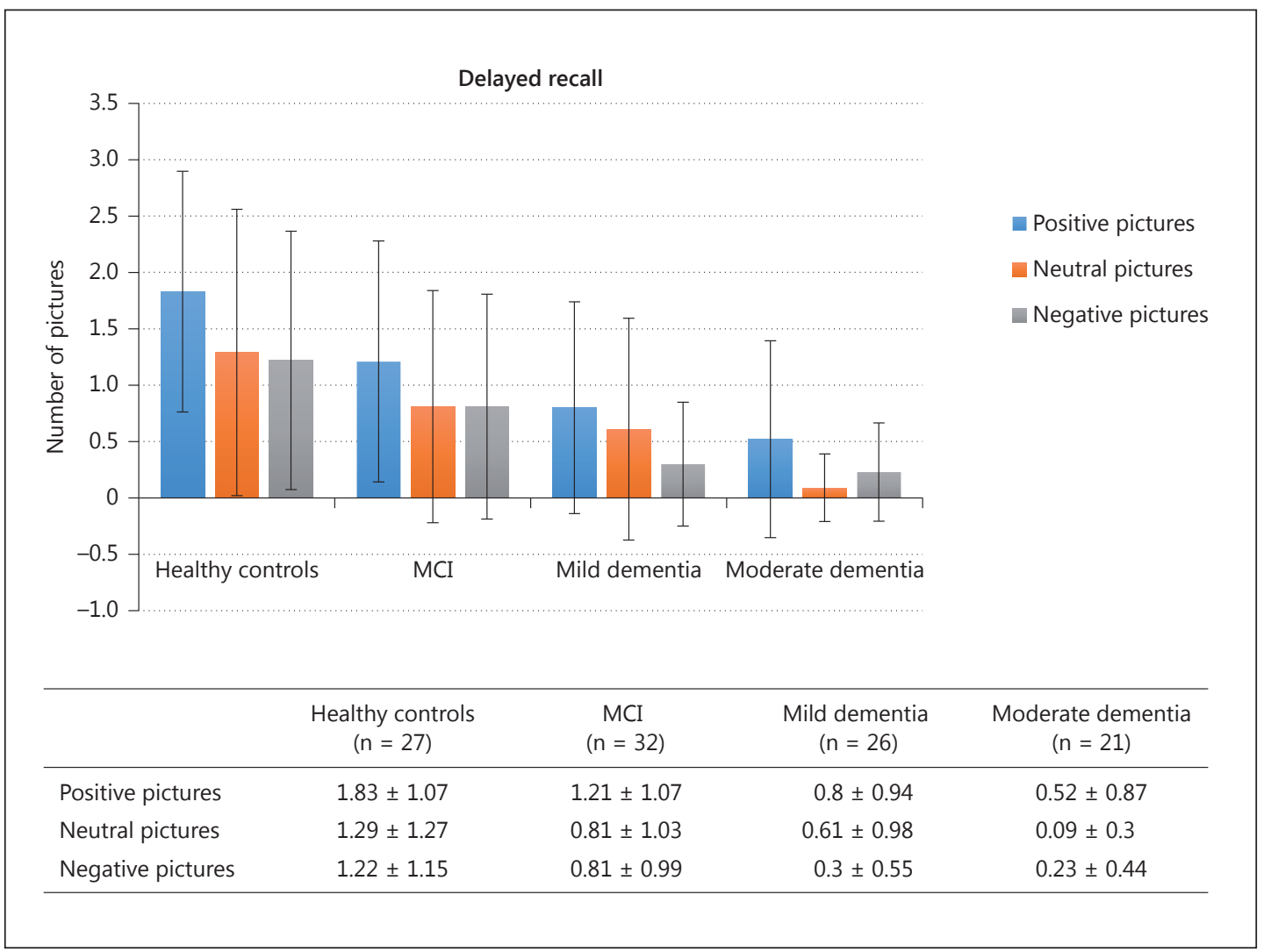

Fig. 2. Mean and standard deviation for the number of recalled positive, negative, and neutral pictures (delayed recall) ocnsidering healthy controls, patients with MCI and both dementia groups.

\section{Recognition Task}

The results of recognition for all groups are illustrated in figure 3. There were significant main effects of diagnosis $\left(\mathrm{F}_{3,103}=16.749, \mathrm{p}<0.001\right)$ and emotional valence $\left(\mathrm{F}_{2,206}=7.049, \mathrm{p}\right.$ $<0.001)$ as well as an interaction effect $\left(\mathrm{F}_{6,206}=2.511, \mathrm{p}=0.023\right)$. The healthy controls and $\mathrm{MCI}$ patients recognized more positive and negative pictures than neutral ones (healthy: $\mathrm{p}<$ $0.001, \mathrm{p}<0.001 / \mathrm{MCI}: \mathrm{p}=0.003, \mathrm{p}=0.039$ ). Patients with mild and moderate dementia were prone to recognize more positive pictures than negative or neutral ones, although this difference was only significant in the group with mild dementia.

\section{Experience of the Picture}

Emotional Valence. As demonstrated in figure 4a, patients with moderate dementia experienced the pictures somewhat different than patients with mild dementia $(p=0.018)$. However, there were no differences between the other groups (diagnosis: $F_{3,97}=3.413, p=$ $0.02)$. As predicted, negative pictures were rated as more negative than positive $(p<0.001)$ and neutral pictures $(\mathrm{p}<0.001)$, and positive pictures were rated as more positive than neutral pictures $\left(\mathrm{p}<0.001\right.$; emotional valence: $\left.\mathrm{F}_{1.672,162.192}=277.227, \mathrm{p}<0.001\right)$. These effects applied to all diagnostic groups (diagnosis $\times$ emotional valence: $F_{5.016,162.192}=1.984$, n.s.).

Arousal. The results are given in figure 4b. Patients with moderate dementia experienced the pictures less intensively than patients with mild dementia $(p=0.009)$ and the controls $\left(p=0.049\right.$; diagnosis: $\left.F_{3,97}=3.896, p=0.011\right)$. As predicted, overall, the positive pictures 
Gorenc-Mahmutaj et al.: The Positivity Effect on the Intensity of Experienced Emotion and Memory Performance in Mild Cognitive Impairment and Dementia

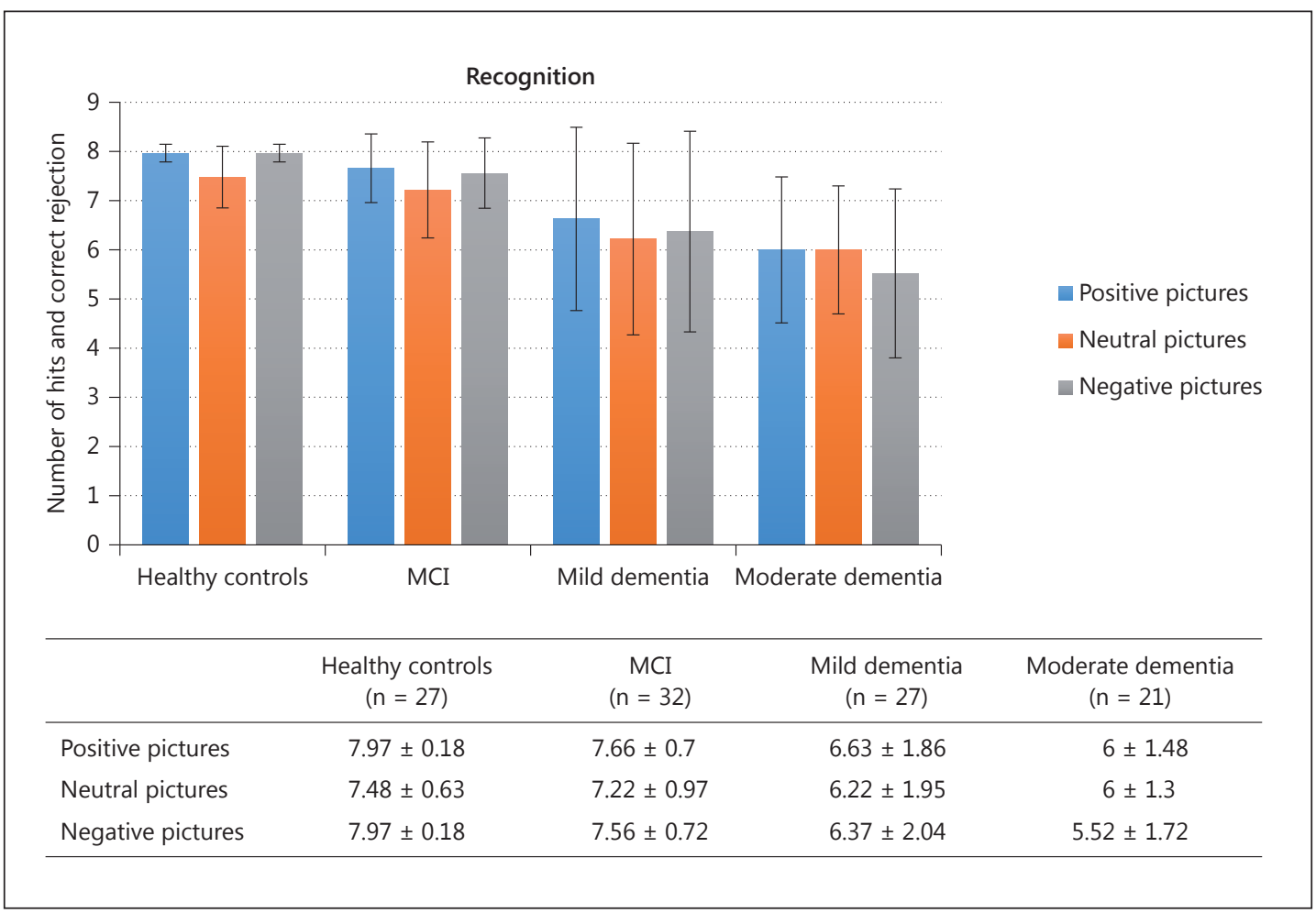

Fig. 3. Mean and standard deviation for the number of hits and correct recognition of positive, negative, and neutral pictures considering healthy controls, patients with $\mathrm{MCI}$ and both dementia groups.

were experienced with the greatest intensity $($ mean $=1.67, \mathrm{SD}=0.51)$ followed by the negative and the neutral ones (emotional valence: $F_{1.678,162.718}=108.687, p<0.001$ ). These effects applied to all groups (diagnosis $\times$ emotional valence: $F_{5.033,162.718}=0.475$, n.s.).

\section{Discussion}

The purpose of the present study was to explore the influence of emotional valence on the intensity of the experience and memory performance and the relationship between the intensity and memory performance in healthy controls and patients with different stages of cognitive decline. We examined subjective experience and explicit memory. As expected, patients with mild and moderate dementia remembered significantly fewer pictures than healthy controls in both recall tasks. The memory performance of patients with MCI was lower than that of healthy controls, butonly for the delayed recall. These data confirm the recall deficits frequently observed in dementia and MCI patients.

Our results confirm the hypothesized positivity effect, with positive pictures being recalled significantly better than negative or neutral ones in all groups under investigation. With respect to the healthy control group, our results are consistent with the findings by Charles et al. [1] who established the positivity effect in healthy middle-aged (41-53 years) and old (65-80 years), but not young (18-29 years), subjects. In contrast, studies considering patients with AD revealed rather inconclusive results. While some studies confirmed the positivity effect in AD patients [14,15], Boller et al. [20] found both positive and negative stimuli to be recalled better than neutral ones. On the other hand, Kazui and colleagues [17, 18], Moayeri et al. [19], and 
Gorenc-Mahmutaj et al.: The Positivity Effect on the Intensity of Experienced Emotion and Memory Performance in Mild Cognitive Impairment and Dementia

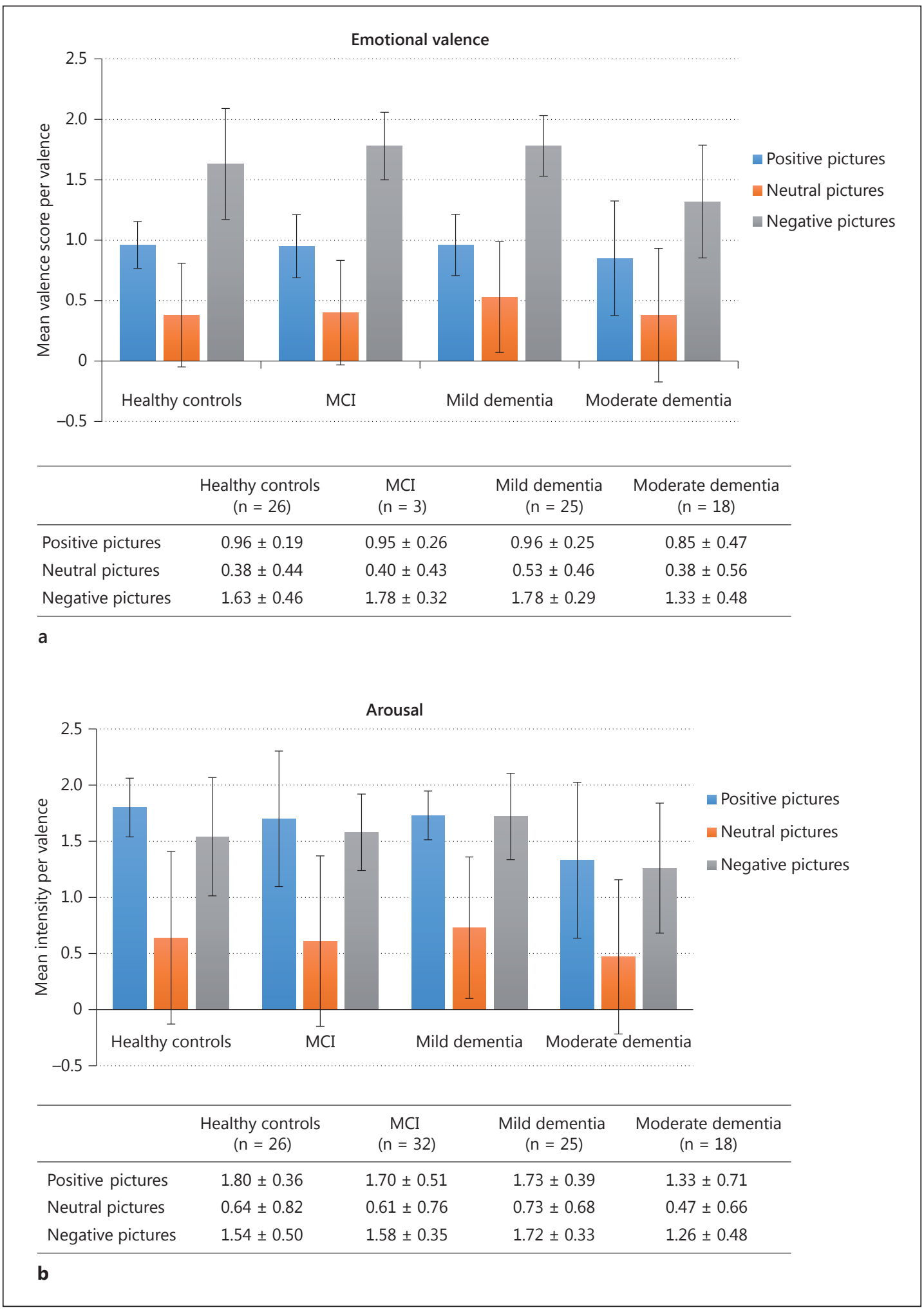

Fig. 4. a Mean and standard deviation for the experience of positive, negative, and neutral pictures considering healthy controls, MCI and both dementia groups. Neutral experience was coded as 0 , positive as 1 and negative as 2. b Mean and standard deviation for the intensity of the experience of positive, negative, and neutral pictures considering healthy controls, MCI and both dementia groups. The lowest intensity was coded as 0 , the middle intensity as 1 and the highest intensity as 2 . 
Gorenc-Mahmutaj et al.: The Positivity Effect on the Intensity of Experienced Emotion and Memory Performance in Mild Cognitive Impairment and Dementia

Fleming et al. [31] described a reversed effect, with negative stimuli being preserved better than positive ones, while other authors were unable to demonstrate an emotional memory effect $[16,21,32]$. However, 3 of the 4 studies yielding a preferential memorization of negative material did not include positive stimuli but instead compared negative with neutral stimuli only. Furthermore, arousal levels evoked by the stimuli were not controlled for in previous studies. Hence, it cannot be excluded that the divergent memory effects reported may be explained by the fact that the respective stimuli triggered varying degrees of emotional reactions across the valence. Thus, not the emotional valence per se but rather arousal levels evoked by the respective stimuli may have influenced memory performance. To meet these methodological constraints, we used a standardized picture set, i.e. the IAPS, in which both positive and negative pictures induced similar arousal levels compared to the neutral ones (neutral pictures: mean $=2.65$; pleasant pictures: mean $=6.30$; unpleasant pictures: mean $=6.48)[30,33]$. Furthermore, the arousal evoked was monitored in each subject. As hypothesized, higher arousal levels were evoked by positive in comparison to negative stimuli while neutral pictures were experienced with the lowest arousal. This finding confirms and extends previous reports $[14,17,34]$ on the intensity of experience in AD patients, which did not differentiate the stimuli according to their valence or solely focused on negative ones.

From a psychological point of view, different emotion regulation strategies are responsible for ensuring that positive pictures are experienced most intensively and remembered best. According to Carstensen [3], positive stimuli are preferentially selected and consequently receive increased attention and more intense arousal subsequently leading to better memory of the particular images.

An alternative regulation strategy would be the cognitive control of negative emotions. A study by Charles et al. [1] showed that both young and old adults consider negative pictures for a longer period of time than positive and neutral pictures. However, during the subsequent recall of images, younger adults remembered more negative pictures, while older adults recalled positive and negative pictures equally. Thus, older adults seem to cognitively control the negativity bias. However, this strategy appears to be unlikely for demented patients due to their impairment in cognitive performance.

From a biological perspective, the role of hippocampal atrophy in early $\mathrm{AD}$ and its association with cognitive decline is of importance [35-37]. Brain regions typically involved in emotional processing (e.g. cingulum, insula and parts of the $\mathrm{PFC}$ ) are widely preserved in AD patients. Using fMRI, Saykin et al. [38] found an increased activation of the PFC while performing cognitive tasks in patients with $\mathrm{AD}$ when compared to healthy controls. Along with this, an increased activation of the PFC correlated with a better performance in semantic and episodic memory tasks indicating a compensatory role of the PFC [22]. Another explanation could offer the interoceptive sensitivity, which is closely connected with the intensity of emotions induced by pictures [39]. The required brain regions, such as the anterior insula, anterior cingulate cortex, parts of the PFC, and the somatosensory cortex, are mostly intact in $\mathrm{AD}$, whereby the perception of physical signals and thus the experience and processing of emotions should be functioning properly.

In addition to the immediate and delayed recall, we also examined the recognition capacity. Our results demonstrate a higher recognition rate for healthy controls and MCI patients in comparison to both dementia groups. Contrary to our expectations, we found an emotional memory effect for both positive and negative pictures in healthy controls and MCI patients, which may refer to ceiling effects. In contrast, patients with mild and moderate dementia preferred positive stimuli in the recognition task, although this difference was only significant in the patients with mild dementia.

The ability of subjects to perceive and recognize the respective pictures as well as the rating of experience intensity have to be discussed as potential confounding variables. 
However, all subjects were able to correctly recognize the images. Experience intensity was protocolled on a rating scale rather than an objective measure such as the Emotional Facial Action Coding System [40] or skin conductance response. Several studies that have conducted such measurements found a close connection between the subjective assessment and the physical reactions in younger and older adults as well as AD patients [14, 41-43].

In summary, our study clearly confirms the positivity effect on the immediate and delayed recall of pictures in a large sample which also includes patients with $\mathrm{MCI}$ and patients with moderate dementia. This effect is linked to a more intense experience but not a more precise recognition of positive rather than negative or neutral pictures. These results may not only facilitate our understanding of memory deficits in MCI and dementia patients but they may also have the potential to be applied in clinical care. With progression of the disease, patients with dementia rely more on nonverbal, emotional aspects of communication as speech and language comprehension are more and more affected. In an independent study, Knebel [44] found that $\mathrm{AD}$ patients could more precisely identify a positive gesture (waving hello) than a negative gesture (tapping one's forehead). From a clinical standpoint, our findings may stimulate longitudinal studies on the effects of cognitive training by using emotionally positive training materials or by embedding training measures in an emotionally reassuring environment.

\section{Acknowledgements}

The present study was commissioned by the Ministry of Social Affairs Baden Württemberg (Evaluation des Gesundheitszustands, der Lebensqualität und der medizinischen Versorgung von Menschen in Pflegeheimen - Evaluation of the state of health, the quality of life and the medical care of nursing home residents).

We acknowledge the financial support of the Deutsche Forschungsgemeinschaft and Ruprecht-Karls-Universität Heidelberg within the funding program Open Access Publishing.

\section{References}

1 Charles ST, Mather M, Carstensen LL: Aging and emotional memory: the forgettable nature of negative images for older adults. J Exp Psychol Gen 2003;132:310-324.

2 Mather M, Carstensen LL: Aging and attentional biases for emotional faces. Psychol Sci 2003;14:409-415.

-3 Carstensen LL: Motivation for social contact across the life span: a theory of socioemotional selectivity. Nebr Symp Motiv 1992;40:209-254.

-4 Carstensen LL, Pasupathi M, Mayr U, Nesselroade JR: Emotional experience in everyday life across the adult life span. J Pers Soc Psychol 2000;79:644-655.

5 Charles ST, Reynolds CA, Gatz M: Age-related differences and change in positive and negative affect over 23 years. J Pers Soc Psychol 2001;80:136-151.

6 Mroczek DK, Kolarz CM: The effect of age on positive and negative affect: a developmental perspective on happiness. J Pers Soc Psychol 1998;75:1333-1349.

7 Bradley MM, Greenwald MK, Petry MC, Lang PJ: Remembering pictures: pleasure and arousal in memory. J Exp Psychol Learn Mem Cogn 1992;18:379-390.

8 Brown R, Kulik J: Flashbulb memories. Cognition 1977;5:73-99.

-9 Pelletier JG, Paré D: Role of amygdala oscillations in the consolidation of emotional memories. Biol Psychiatry 2004;55:559-562.

10 Cabeza R, Dolcos F, Graham R, Nyberg L: Similarities and differences in the neural correlates of episodic memory retrieval and working memory. Neuroimage 2002;16:317-330.

11 Mather M, Canli T, English T, Whitfield S, Wais P, Ochsner K, Gabrieli JD, Carstensen LL: Amygdala responses to emotionally valenced stimuli in older and younger adults. Psychol Sci 2004;15:259-263.

12 Mori E, Ikeda M, Hirono N, Kitagaki H, Imamura T, Shimomura T: Amygdalar volume and emotional memory in Alzheimer's disease. Am J Psychiatry 1999;156:216-222.

13 Ikeda M, Mori E, Hirono N, Imamura T, Shimomura T, Ikejiri Y, Yamashita H: Amnestic people with Alzheimer's disease who remembered the Kobe earthquake. Br J Psychiatry 1998;172:425-428.

14 Hamann SB, Monarch ES, Goldstein FC: Memory enhancement for emotional stimuli is impaired in early Alzheimer's disease. Neuropsychology 2000;14:82-92. 
15 Kalenzaga S, Clarys D: Self-referential processing in Alzheimer's disease: two different ways of processing selfknowledge? J Clin Exp Neuropsychol 2013;35:455-471.

-16 Abrisqueta-Gomez J, Bueno OF, Oliveira MG, Bertolucci PH: Recognition memory for emotional pictures in Alzheimer's patients. Acta Neurol Scand 2002;105:51-54.

17 Kazui H, Mori E, Hashimoto M, Hirono N, Imamura T, Tanimukai S, Hanihara T, Cahill L: Impact of emotion on memory: controlled study of the influence of emotionally charged material on declarative memory in Alzheimer's disease. Br J Psychiatry 2000;177:343-347.

-18 Kazui H, Mori E, Hashimoto M, Hirono N: Enhancement of declarative memory by emotional arousal and visual function in Alzheimer's disease. J Neuropsychiatry Clin Neurosci 2003;15:221-226.

19 Moayeri SE, Cahill L, Jin Y, Potkin SG: Relative sparing of emotionally influenced memory in Alzheimer's disease. Neuroreport 2000;11:653-655.

20 Boller F, El Massioui F, Devouche E, Traykov L, Pomati S, Starkstein SE: Processing emotional information in Alzheimer's disease: effects on memory performance and neurophysiological correlates. Dement Geriatr Cogn Disord 2002;14:104-112.

-21 Kensinger EA, Brierley B, Medford N, Growdon JH, Corkin S: Effects of normal aging and Alzheimer's disease on emotional memory. Emotion 2002;2:118-134.

-22 Grady CL, McIntosh AR, Beig S, Keightley ML, Burian H, Black SE: Evidence from functional neuroimaging of a compensatory prefrontal network in Alzheimer's disease. J Neurosci 2003;23:986-993.

23 Davidson RJ, Irwin W: The functional neuroanatomy of emotion and affective style. Trends Cogn Sci 1999;3: 11-21.

24 Grimm S, Beck J, Schuepbach D, Hell D, Boesiger P, Bermpohl F, Niehaus L, Boeker H, Northoff G: Imbalance between left and right dorsolateral prefrontal cortex in major depression is linked to negative emotional judgment: an fMRI study in severe major depressive disorder. Biol Psychiatry 2008;63:369-376.

25 Levy R: Aging-associated cognitive decline. Working Party of the International Psychogeriatric Association in collaboration with the World Health Organization. Int Psychogeriatr 1994;6:63-68.

26 Schönknecht P, Pantel J, Kruse A, Schröder J: Prevalence and natural course of aging-associated cognitive decline in a population-based sample of young-old subjects. Am J Psychiatry 2005;162:2071-2077.

27 World Health Organization: International statistical classification of diseases and related health problems. 2009. http: www.who.int/classifications/icd/en/.

-28 Folstein MF, Folstein SE, McHugh PR: 'Mini-mental state'. A practical method for grading the cognitive state of patients for the clinician. J Psychiatr Res 1975;12:189-198.

29 Yesavage JA, Sheikh JI: Geriatric depression scale (GDS) recent evidence and development of a shorter violence. Clin Gerontol 1986;5:165-173.

30 Lang PJ, Bradley MM, Cuthbert BN: International Affective Picture System (IAPS): Technical Manual and Affective Ratings. Gainesville, Center for Research in Psychophysiology, 1999.

-31 Fleming K, Kim SH, Doo M, Maguire G, Potkin SG: Memory for emotional stimuli in patients with Alzheimer's disease. Am J Alzheimers Dis Other Demen 2003;18:340-342.

-32 Kensinger EA, Anderson A, Growdon JH, Corkin S: Effects of Alzheimer disease on memory for verbal emotional information. Neuropsychologia 2004;42:791-800.

33 Keil A, Bradley MM, Hauk 0, Rockstroh B, Elbert T, Lang PJ: Large-scale neural correlates of affective picture processing. Psychophysiology 2002;39:641-649.

34 Satler C, Garrido LM, Sarmiento EP, Leme S, Conde C, Tomaz C: Emotional arousal enhances declarative memory in patients with Alzheimer's disease. Acta Neurol Scand 2007;116:355-360.

- 35 Pantel J, Schröder J (eds): Zerebrale Korrelate klinischer und neuropsychologischer Veränderungen in den Verlaufsstadien der Alzheimer-Demenz: Untersuchungen mit der quantitativen Magnetresonanztomographie. Darmstadt, Steinkopff, 2006.

-36 Zola-Morgan S, Squire LR, Amaral DG: Human amnesia and the medial temporal region: enduring memory impairment following a bilateral lesion limited to field CA1 of the hippocampus. J Neurosci 1986;6:2950-2967.

37 Squire LR: Memory and the hippocampus: a synthesis from findings with rats, monkeys, and humans. Psychol Rev 1992;99:195-231.

-38 Saykin AJ, Flashman LA, Frutiger SA, Johnson SC, Mamourian AC, Moritz CH, O’Jile JR, Riordan HJ, Santulli RB, Smith CA, Weaver JB: Neuroanatomic substrates of semantic memory impairment in Alzheimer's disease: patterns of functional MRI activation. J Int Neuropsychol Soc 1999;5:377-392.

-39 Herbert BM, Pollatos O: Interozeptive Sensitivität, Gefühle und Verhaltensregulation. Z Neuropsychol 2008;19: 125-137.

40 Ekman P, Friesen WV: Facial Action Coding System. A Technique for the Measurement of Facial Movement. Palo Alto, Consulting Psychologists Press, 1978.

41 Buchanan TW, Denburg NL, Tranel D, Adolphs R: Verbal and nonverbal emotional memory following unilateral amygdala damage. Learn Mem 2001;8:326-335.

42 Denburg NL, Buchanan TW, Tranel D, Adolphs R: Evidence for preserved emotional memory in normal older persons. Emotion 2003;3:239-253.

43 Seidl U, Lueken U, Thomann PA, Kruse A, Schroder J: Facial expression in Alzheimer's disease: impact of cognitive deficits and neuropsychiatric symptoms. Am J Alzheimers Dis Other Demen 2012;27:100-106.

44 Knebel M: Kommunikation bei Demenz. Validierung eines Instruments zur Erfassung kommunikativer Verhaltensweisen bei Demenzen. Psychosoziale Interventionen zur Prävention und Therapie der Demenz. Berlin, Logos Verlag, 2015, vol 11 (Dissertation Universität Heidelberg 2013). 